\title{
The Interactive Dimension of Creating Cultural Artifacts Using Agile Methodologies
}

\author{
Rafał Wiśniewski \\ National Centre for Culture / Cardinal Stefan Wyszyński University in \\ Warsaw, Poland
}

\section{Izabela Bukalska \\ Cardinal Stefan Wyszyński University in Warsaw, Poland}

DOI: http://dx.doi.org/10.18778/1733-8077.16.4.12

\section{Keywords:}

Symbolic

Interactionism;

Creative Sectors;

Creativity; Agile

Methodologies

\begin{abstract}
The authors consider symbolic interactionism to be a suitable theoretical framework to analyze projects in creative sectors because it affords ample space for individual and collective creativity. Furthermore, teams working on different cultural artifacts establish a negotiated order (interactionist term coined by A. L. Strauss) among artists, managers, the audience, and sponsors, et cetera, by discussing and translating various meanings and perspectives. This is especially noticeable when projects are managed using an agile methodology. The application of agile methodologies in creative sectors is a relatively new idea, although it seems to be in harmony with the nature of artistic work. For instance, it implies the acceptance of unpredictability and flexibility while also recognizing the ability and individuality of project participants. There are also specific problems related to the personalities of the artists and the irregularities and discontinuities inherent in the process of creation. The first part of the article raises the topic of creativity in symbolic interactionism. This perspective is subsequently extended to teamwork in creative sectors employing the description of collective work in Howard Becker's book entitled Art Worlds as an example. The authors reflect on other contemporary works explaining the cultural shift transpiring during the move from the analog age to the current digital age and its influence on the process of creation in the world of artists. This leads to a discussion of distributed agility, a concept stemming from agile management. The various agile methods are mentioned and shortly characterized; we also present a succinct depiction of historical perspective. The literature on the use of agile methods in creative sectors is referred to along with some of the challenges they face. The need to develop an agile management methodology specifically for creative industries is emphasized. This article utilizes the literature on symbolic interactionism to explain group dynamics by drawing analogies with agile management.
\end{abstract}


Rafał Wiśniewski is an Associate Professor at Cardinal Stefan Wyszyński University in Warsaw. He specializes in the sociology of culture and intercultural communication. He is the director of the National Centre for Culture in Poland.

email address: r.wisniewski@uksw.edu.pl
Izabela Bukalska is an Assistant Professor at the Sociology of Culture Department at Cardinal Stefan Wyszyński University in Warsaw. She is a secretary of the Section of Qualitative Sociology and Symbolic Interactionism of the Polish Sociological Association. She conducts research using grounded theory methodology.

email address: i.bukalska@uksw.edu.pl
Faulkner and Becker show that musicians collectively negotiate and improvise their way to a successful performance. Players must explore each other's areas of expertise, develop an ability to fake their way through unfamiliar territory, and respond to the unpredictable demands of their audience-whether an unexpected gang of polka fanatics or a tipsy father of the bride with an obscure favorite song. [Do You Know..? The Jazz Repertoire in Action, 2009, back cover review]

\section{Creativity in Sociological Sciences}

In sociological theory, one was not always perceived as a creative ${ }^{1}$ individual. The attribute of creativity was assigned to outstanding people,

\footnotetext{
${ }^{1}$ Creativity in general understanding is connected with the ability to go beyond established patterns. Krzysztof Konecki (2019) enumerates the circumstances that must occur for something to be deemed to be creative, such as collective acceptance, appreciation by a specific audience, historical adequacy, et cetera. Arthur Cropley (2011:511) states, "[t]he modern definition of creativity has broadened from a focus on esthetics towards practical products in science, technology, or business, and away from the creation of beauty towards overcoming competition." Although esthetics form the core focus in these considerations, other aspects will be presented because collective work in creative industries is predicated on various specialists cooperating with one another.
}

as is the case with Weber's charismatic leaders and Znaniecki's "abnormal perverts." Rather, as Gabriel Tarde observed, social continuity was maintained thanks to the ability to imitate, sometimes interrupted by creative personalities. Over time creativity began to be treated as an attribute of human beings. Georg Simmel wrote about the growing tension between subjective and objective culture, in other words, the spontaneous work of individuals and the established heritage that limits them.

Creative activity can be seen at different levels of human activity. Symbolic interactionists took note of them in the basic interactions between individuals. Even though he distinguishes the subjective and objective elements of the self in personality, George Herbert Mead writes about the social creativity initiated by the former. However, creative energy is sublimated and limited by the latter, an "organized collection of other people's attitudes." According to Blumer, symbolic interactionism shows that society is a collection of individuals in an endless creative process $^{2}$ (which does not mean

\footnotetext{
${ }^{2}$ In contrast to Kuhn's interactionist Iowa School, which limited the creative abilities of individuals because of the existence of a core self and a social structure, for instance.
} 
that there are no institutional limitations). The course of symbolic interaction is to some extent unpredictable because it is based on individuals' freedom of interpretation. Various "connected actions," such as a parliamentary discussion or a commercial transaction, follow certain models, but each case has to be recreated to some extent. In groups, new problematic situations that do not comply with the existing rules of conduct always emerge; the interpretations and actions of individuals exert an impact on changes in the course of connected actions and in society itself.

Ed Petkus (1996) analyzes the motivations for creative behavior, especially for the creative fulfillment of social roles. He bases his considerations on symbolic interactionism and refers to the concept of role-identity developed by McCall and Simmons, as well as to the concept of the looking-glass self. According to the latter, individuals want to be perceived as not only belonging to their role, but also as being creative in its performance. The authors mention other researchers who combine symbolic interactionism with creativity: Hormuth (1983) combined the originality of answers (in interaction) with self-focused attention, while Chapman and Carrigan (1993) associated originality with the size of the group in which a given task was performed (an inversely proportional relationship).

Reflection is given to creativity in research methodology. According to Krzysztof Konecki (2019:7), qualitative research, in particular, is considered to be creative due to the lack of strict rules and methodological freedom, which allows for creative design and research activities. Practitioners of grounded theory methodology (symbolic interactionism is often the meta-theory in this case) of- ten write about theoretical sensitivity that enables researchers to yield a glimpse of new regularities and phenomena in the data. Theoretical sensitivity is a characteristic that develops as research experience is gained. There are many techniques to enhance research creativity, for example, contemplative practices (Konecki 2018) and other practices cited by Marek Gorzko (2016) in the literature on the subject (2016): the dual nature of thinkingrational and free, removing blockages and the attitude of "patience," and theoretical comparison techniques. However, these examples pertain to individual practices. Many textbooks on grounded theory methodology advise using teamwork as a means to cultivating creativity because it entails a clash of perspectives and triangulation of researchers.

Some symbolic interactionists participated in a genuinely creative process, which is particularly important for these deliberations. In this context the analyses conducted by Howard Becker and Robert R. Faulkner (both sociologists and jazz musicians) deserve mention. ${ }^{3}$ Faulkner deliberates on the essence of the complex interactive sequence of a jazz concert, whether on stage or in a studio. On the one hand, it involves the interpretation and improvisation of free creative individuals; on the other hand, it calls for constantly thinking about who the partners are and skillful and harmonious reactions to given impulses while also adhering to the pertinent conventions and rules.

\footnotetext{
${ }^{3}$ George Herbert Mead (1926), father of symbolic interactionism, put the aesthetic experience in the context of his conception in "The Nature of Aesthetic Experience." Philipp Vannini and Dennis Waskul (2006) provide a detailed analysis of interaction mediated (and not only) with music, in the article "Symbolic Interaction as Music: The Esthetic Constitution of Meaning, Self, and Society."
} 
The level and intensity of interplay between the routinized and the innovative vary...within bands, and across bands. Improvising together is collective action, concerted work that couples these elements, both within players as they solo with other musicians, and between players as they immediately respond to one another on the bandstand... or wherever they perform. The musical activity is simultaneously deliberate and spontaneous, imitative and experimental, routinized and innovative. [Becker et al. 2006:92]

Howard S. Becker used a jazz metaphor to analyze the interactions of individual creativity and the social limitations imposed on it (Katz 1994). In his book, Art Worlds, he addresses the problem of artistic criticism and the development of aesthetic theories, which can impede artistic creativity. He observes that influences usually run in the opposite direction.

R. Keith Sawyer (2003:96), in his book Group Creativity: Music, Theater, Collaboration, when referring to Dewey's pragmatism and symbolic interactionism, analyzes how group creativity is born during improvisation. He refers to jazz concerts and improvisation theater. Creativity in these groups is characterized by processability, unpredictability, intersubjectivity, complex communication, and emergence (the performance of the group is more creative and valuable than the sum of its members' individual contributions). He also stresses the importance of group interaction, acceptance, and development of each artist's contribution. In order to understand this interaction, interactional synchrony, flow, chemistry, and group dynamics are needed. Sawyer also attempts to ascertain the degree of improvisation in a group and enumerates 11 dimensions to make that assessment. He stresses that group creativity cannot be explained by employing a traditional structural model because it is an unpredictable, collective, and emergent phenomenon.

\section{Creative Sectors}

In his Art Worlds, Becker (1984) describes the functioning of collectives in which some cultural artifacts are created. Artistic circles constitute a distinct sub-world. Using the example of a film, Becker shows the specificity of the division of labor among artists, which is often undefined and based on performing double and triple roles. Considering that artistic work needs to be promoted, another group of specialists, namely, distributors are involved. They differ from artists in terms of their attitude towards the work and the organization of work. They are charged with the task of striving to bring order to a chaotic creative process. ${ }^{4}$ Sponsors, representatives of state institutions, and art critics may also play a part as additional actors. ${ }^{5}$ This description shows the limitations imposed on creators. At the same

\footnotetext{
${ }^{4}$ Izabela Ślęzak (2009) describes in her monograph another field of creative activity, namely, poetry. Beginning from the symbolic interactionism framework she traces the long process of acquiring a new identity-becoming a poet. The last two stages of the process- "intensive career-building" and "mature career" - consist precisely in relations with poetry circles and the diverse social world of poetry.

${ }^{5}$ This situation also resembles the interactionist concept of "negotiated order." Anselm Strauss illustrates this concept using the example of a psychiatric hospital, where many different actors are engaged (physicians, residents, interns, nurses, social workers, nutritionists, clerical personnel), for the common general aim of achieving a patient's well-being. All these members have different training and professional socialization, various experiences, and different personal backgrounds, leading to multiple theories regarding how the general tasks will be completed and how labor will be divided (Strauss 1963). When applying agile management in a work team, the situation becomes more dynamic and the roles become more fluid.
} 
time, it demonstrates that this system of work as described is needed to produce and disseminate their products.

The question arises whether the remarks made in Art Worlds are still applicable. After all, that book was first published in 1982 and reflects the circumstances on the American market at that time. Over time, the pace of change has dramatically increased, requiring the rapid delivery of products, addressing and adjusting to contemporary needs, responding to the actions taken by competitors and customers who are constantly searching for something new. The ensuing changes pose a significant challenge in creative project management.

Moreover, Becker's book refers to the analog world of art present in the $20^{\text {th }}$ century. Music and, more generally, art have undergone a major transformation in the digital age. In their analysis of new music industries, Hughes, Evans, Morrow, and Keith (2016) developed the concept of "distributed agility" (this term is derived from agile management). They point out that in the current digital age, artists, managers, and all of their collaborators engaged in the process of creation have become more alert and "reactive" to the choices made by their audiences. The previous networks and mechanics of artistic recognition have changed. Guy Morrow (2018:47) expounded on their idea as follows, "artist managers have to be agile in order to react quickly enough to help artists seize opportunities in the digital age and help them manage the risks that have been externalized to them...Instead of investing time and money in what they 'assume' will receive attention from the audiences, artist co-managers, particularly those working across different international territories, need to deploy distributed agile methods." He also suggests that new research areas should include the idea generation processes transpiring in distributed agile and self-organizing teams. Dezutter's (2011) concept of distributed creativity may also prove to be useful in this context.

These processes are inherent in the attention economy (Simon 1971). The trend towards digitalizing cultural content has deprived some artistic works of the audience's attention. At the same time, it has significantly augmented the body of other artistic content. Recipients are inundated with an overabundance of content to consume, meaning that their attention becomes an important albeit scarce resource.

Recognizing the pithy role played by the creative industries in economic development, at the national and European levels alike, is vitally important. Andreas Reckwitz (2012:166) writes that the creative industries were originally complementary to other industries. Design, advertizing, and fashion merely added value to functional objects; over time, these industries have been revalued and transformed into "leading cultural formats." The concept of creative industries/sectors itself dates back to the 1990s. However, as Rafał Wiśniewski and Tomasz Kukołowicz (2017:103) point out, "creative industries are characterized by a relatively high economic potential. They include not only creative areas of high artistic value, but also popular culture as a whole."

As defined by the EU (INTERREG IVC Report ${ }^{6}-$ Creative Industries), Cultural and Creative Sec-

\footnotetext{
${ }^{6}$ The INTERREG IVC program was implemented within the framework of the European Territorial Cooperation objective,
} 
tors (CCIs) include Architecture, Archives and Libraries, Artistic Arts, Audiovisual (Film, TV, Video Games, Multimedia), Cultural Heritage, Design (including Fashion), Festivals, Music, Performing and Visual Arts, Journalism and Radio. The report also defines the characteristics of entities working in the cultural and creative sectors: a small number of employees (usually fewer than 10), highly qualified people who frequently work as freelancers on temporary project-related contracts. The development of CCIs fosters the creation of networks in narrow specializations and clusters or other forms of cooperation.

To conclude, special management techniques should be applied in artistic and creative projects. This may also entail the development of novel methods specifically designed for activity in this area.

\section{Agile Methodologies in Project Management}

In 2004 Jim Highsmith wrote about a quiet revolution in the market to which managers and engineers have to adapt. He notes that other industries, such as the IT, pharmaceutical, and car manufacturing industry exert constant pressure for innovation accompanied by falling research and development (R\&D) costs. The original method of manufacturing products based on meticulous upfront planning and a linear cascade structure proved to be inefficient. Former practices did not fit in contemporary "fleeting environments" in which products are and were produced (Highsmith 2004:25). It was therefore necessary to shift to adaptive manufacturing. The author

supported in accordance with the policy assumptions of EU Structural Funds. emphasizes that if production changes, project management must also change. It must focus on speed, mobility, and experimentation.

His book serves as a manual for agile project management. Three years earlier, a group of 17 software engineers had formulated the memorable Manifesto for Agile Software Development (Beck et al. 2001) concisely depicting vital assumptions and values for the new types of teams to function:

- people and interactions rather than processes and tools

- operating software rather than extensive documentation

- cooperation with the customer rather than formal arrangements

- responding to changes rather than following the plan

Change management is inevitable in the manufacturing process, which also entails innovation; so is the analysis of deviations from the plan. The ability to adapt to changing conditions in the design is a success. No wonder initial plans are rather hypotheses than predictions (Highsmith 2004). Craig Larman (2004), while recognizing the legitimacy of abandoning precision planning, notes that both customers and users at the beginning of a project are not sure what they want, and have problems with the formulation of requirements; many details are revealed only during the project implementation, implementation details are impossible to guess at the beginning. The customer's way of thinking evolves during the product development process; one should not forget about external forces (e.g., competition) leading to a change in requirements. 
Table 1. Comparing Agile Methodologies.

AGILE METHODOLOGY

Extreme Programing (XP)

Scrum

Feature-Driven Development

Dynamic Systems Development Method (DSDM)

Lean Software Development

Kanban Method

Crystal Family
EMPHASIS

Efficiency, customer focus and feedback, and quality

Teaming, organizing work

Iterative development of user focused features

Structured approach to rapid

development, collection of best practices
FOUNDER(S)

Kent Beck
Jeff Sutherland and Ken Schwaber

Jeff De Luca
Eliminate work that doesn't create customer value
Mary and Tom Poppendieck

David J. Anderson

Alistair Cockburn
Visualize and manage workflow, just-in-time development

People, communication, process

rigor map to product and

organizational dynamics
DSDM Consortium

Source: Ashmore and Runyan (2015:51).

The table above shows some of the best-known types of agile methodology. Most of them were designed before Jim Highsmith's work in 2004 or originate from older concepts signaled in the 1990s. Other concepts not included in the table also exist, such as the Systems Development Life Cycle (SLDC), which some consider being inflexible and too time-consuming for the present day; now some attempts are being made to adjust it to current needs (Harris 2019).

There are also important techniques used in contemporary agile methodologies. The Digital Feedback Loop proposed by Microsoft is based on five con- nected pillars: Engage Customers, Empower Employees, Optimize Operations, Transform Products, Data \& Intelligence (Thibeault 2018). We should also mention Cognitive, Intelligent Connected Product (Cyran and Dybka 2019:243) extended across the product lifecycle and supported by enabling technologies such as Artificial Intelligence. Practitioners also emphasize the role played by the User Experience (UX) technique, especially with the participation of the end-users of a given product. UX is a more complex practice of engaging customers in the process, often with the use of mobile devices. Agile teams often neglect the UX stage even though making this invest- 
ment significantly mitigates the risk of product failure (Convertino and Frishberg 2017:35-36).

In agile methodology, there is a clear orientation towards creating a self-organizing and self-disciplining team. Project groups are usually small and have a flat, non-hierarchical structure. Respect for the individual and their competence is emphasized. All team members should feel responsible for the project and are kept informed about the work of the other participants in daily meetings. Sometimes, they take over each other's functions. They are also able to admonish a manager (courage is one of the five basic values of the SCRUM related methodology). This emphasis on individual creativity makes it harder to introduce agile methodologies in the collectivist and conformist cultures of the East (Ramesh et al. 2017:215).

When analyzing the use of agile methods in Big Data projects, the author advises the selection of omnibuses rather than narrow specialists for inclusion in teams (Jurney 2014:24-25). The former are able to undertake various tasks and communicate more efficiently with the team. He stresses that, as creative workers, they deserve working conditions that allow them to focus their attention and utilize their special working conditions. Agile is also referred to as a social movement aimed at creating a good, adaptable working environment that is able to provide innovative products. The contention in agile textbooks that APM (adaptive project management) supports artists, not managers, is important from the point of view of our analysis (agile sectors involving artists).

\section{Agile Methodologies and Creative Industries}

Agile methodologies have been developed based on the experience of the IT sector and specifically for its management. In 2018, Papadakis and Tsironis analyzed 71 projects, and only four concerned other sectors (the service sector and the construction industry). Kiril Angeuelov (2019) writes about the use of agile methodologies in management in public administration and university classes.

Meanwhile, the creative sector has started to advocate more vocally, though still modestly, the use of agile methodologies citing their prospective beneficial influence. Managers and researchers who have followed computer game developers, who are most closely related to the IT sector, have already amassed some experience. Damian Hodgson and Louise Briand (2013) have analyzed a Canadian computer game studio. All 12 team members-directors, producers, game designers, leaders, programers, artists, and animators-were interviewed. Several months of participatory observation took place during scrums, sprint reviews, brainstorming sessions, poker planning sessions, et cetera. They regularly stressed the group's egalitarian and democratic structure, but the real challenge proved to be eradicating former power structures and stronger decision-making centers in the group. An important observation articulated by several members of the group was that "artists aren't agile." Artists and animators failed to work at the pace set by the group and refused to meet some of its demands. ${ }^{7}$ Certainly, apart from strong creative personalities, the specificity of creative work was at play. As the manager said, in programing everything is Cartesian, but in art, there are days when you are inspired and days when you are not-it is difficult to manage and direct it. Artists were therefore excluded from at least

\footnotetext{
${ }^{7}$ In fact, issues involving the retention of individual creativity and some artistic freedom need to be addressed in the course of the process of designing agile methods for creative sectors.
} 
a few agile methodologies and procedures, including tracking tasks and poker planning; they were limited to asking general questions about progress and proposing possible assistance. The authors conclude that the work of aesthetic and symbolic nature is relatively resistant to control practices even in flexible methods such as agile methodologies, not to mention the former cascade management models. They pointed out that there is an urgent need for extensive and critical research into the control of such projects.

Thomas Paris and Sihem Ben Mahmoud-Jouini (2019) conducted research in 42 companies operating in 12 sub-sectors of creative industries. Interviews, observations, analysis of archival documents, and conference materials made it possible to identify challenges in project management in these sectors: a high degree of uncertainty as to the audience's product perception and acceptance; the need to combine freedom and intuition of creation with economic and market analyses; the initial multitude and diversity of ideas that must be concentrated in one particular product; the diversity of actors involved in the project-strong personalities that require a wide range of autonomy and freedom, but also others seeking coordination and organization.

Four practices have also been identified that make up the creative process in the projects of companies operating in creative sectors: inspiration consisting in immersing oneself in environments different from one's own, contact, and conversation with people operating in different fields; framing the idea into a compact form in order to outline the direction in which it will be developed; creating a prototype by transforming the idea into a material reality (scenarios, scripts, models depicting the structure); vali- dation through selecting, modifying, or rejecting the inadequate parts (often after consulting the team) of fragments. The authors point out that in creative sectors these four practices do not occur sequentially (although they are arranged in a logical sequence of consequences and in other types of projects this sequence may occur), but they may take place in different combinations. Citing the mismatch between the linear management model and "creative projects," researchers suggest that agile methodologies are suitable. At the same time, they formulate some recommendations regarding the challenges faced by managers.

Thomas Paris, Gerald Lang, and David Masse (2020) analyze the distinct nature of creative industries using the example of the perfume sector. They introduced the concept of "contextual creativity," a course of creative creation and its effect depends on the environment in which an individual operates. The group management style is very important here.

Kiril Angeuelov (2019) analyzes the applicability of the principles contained in the "agile manifesto" to individual creative sectors. Thus, the assumption of; 1) achieving customer satisfaction through early and continuous software delivery is possible in the case of advertising and architecture, where there is the greatest probability of discrepancies materializing between the customer's vision and the work of the team; 2) frequent software delivery is possible in the case of archival and library projects; 3) frequent response to changes in customer requirements is most probable in architecture, advertising, and in some cultural sectors; 4) cooperation between business stakeholders and developers during the project, that is, clients and experts, is most probable in advertising, design, and architecture; 5) support, trust, and 
motivation of employees-correspond to all sub-sectors, although as mentioned above-it is particularly problematic in teams composed of renowned artists; 6) enabling face-to-face interaction is possible in any $\mathrm{CI}$ team, especially since it is usually not frequent or invasive; 7) operating software as a measure of progress is possible in architecture and advertising; 8) constant pace of progress of the project is linked to motivation, the author does not mention the difficulties associated with the irregular and "volatile" nature of artistic work, but certainly this difficulty is present in many subsectors; 9) focus on technical details that support agility-this is essential in architecture and interior design; 10) simplicity-this is the most difficult principle to apply in the creative sectors-the products produced in these sectors are not (according to the author) the result of simplicity in the manufacturing process; 11) self-organizing teams creating specific architectures, requirements and designs-here the author notes that although such organizational independence of the group is possible (again) in architecture, design, or advertising, in the sphere of culture the role of leader is indispensable (orchestra conductor, director in a film or theater); 12) regular reflection on efficiency is possible in architecture and design, and hindered in architecture where there are precise legal requirements and limitations, also in cultural sectors where the creators are guided by other values other than economics. Angeuelov's analysis, therefore, showed the relevance of agile principles in creative sector projects: in some of them, they are totally relevant, while in others they are only partially relevant (architecture, media, and culture).

\section{Conclusion}

These few works concerning the application of agile methodologies in project management in cre- ative sectors clearly indicate their adaptation to the specifics or distinct nature of this type of complex creative process. Becker's Art Worlds portrays the characteristics of some creative sectors (without using this name) and outlines the need for an extraordinary and flexible approach to management. It is certainly worthwhile to develop or create agile methodologies for CI projects with respect to their specific challenges.

Symbolic interactionists emphasize the importance of entering roles in an efficient manner and the ability to anticipate other people's behavior in a team, which was perfectly illustrated by G. H. Mead (1934:256) in his example of playing baseball:

The very organization of the self-conscious community is dependent upon individuals taking the attitude of the other individuals. The development of this process, as I have indicated, is dependent upon getting the attitude of the group as distant from that separate individual-getting what I have termed "generalized other." I have illustrated this by the ball game, in which the attitudes of a set of individuals are involved in a cooperative response in which the different roles involve each other. In so far as a man takes the attitude of one individual in the group, he must take it in its relationship to the action of the other members of the group; and if he is fully to adjust himself, he would have to take the attitudes of all involved in the process. The degree, of course, to which he can do that is restrained by his capacity, but still in all intelligent processes we are able sufficiently to take the roles of those involved in the activity to make our own action intelligent.

These methodologies are smart, or agile, to put it differently. Mead perfectly portrays the ideal type of management in a self-organizing group attempting 
to achieve a single purpose and presents an ideal understanding and the responsible attitude shown by its team members. This ideal is desirable in the creative sectors, but it is not always achievable because the varying dynamics of work in artistic creation must be factored into the equation.

Theoreticians in agile methodologies mention the possibility of individual team members changing roles. Symbolic interactionist Ralph H. Turner (1990:88) wrote about role changing, which he defined as: "change in the shared conception and execution of typical role performance and role boundaries." New roles can be created or disappear, they can change quantitatively or qualitatively by reinterpreting their meaning (Turner 1990:88). Many modifications of social roles are caused by social changes over time and that is the nature of participation in projects now managed in a new way.

\section{References}

Angeuelov, Kiril. 2019. "Research for Usefulness of Agile Methods in Creative Business." Conference Paper 2019 published in: International Conference on Creative Business for Smart and Sustainable Growth (CREBUS). Sandanski, Bulgaria: IEEE.

Ashmore, Sondra and Kristin Runyan. 2015. Introduction to Agile Methods. Upper Saddle River, NJ: Addison.

Beck, Kent et al. 2001. "Manifesto for Agile Software Development." Agile Alliance. Retrieved October 04, 2020 (http://agilemanifesto.org/).

Becker. Howard S. 1984. Art Worlds. Berkeley, CA: University of California Press.
Transparency in the decision-making process and participation in management are other agile assumptions, which at the same time suggest an analogy to acting in the open context of consciousness described by Glaser and Strauss (1967). Such a situation of non-hierarchical creation of cultural artifacts in creative sector companies is what Blumer (1969:18) refers to as joint actions. In such an interactive chain, there is a characteristic division of labor as noted by the author. A mature theory of symbolic interactionism can help practitioners of agile methodologies comprehend the processes taking place in observed or coordinated groups. Reading numerous social studies based on the meta-theory of symbolic interactionism can also provide interesting examples of problematic situations and their solutions. Grounded theory methodology inspired by interactionism can provide valuable lessons regarding theoretical concepts that can be used immediately in project management strategic planning.

Becker, Howard S. and Robert A. Faulkner. 2009. "Do You Know...?": The Jazz Repertoire in Action. Chicago: University of Chicago Press.

Becker, Howard S. et al. 2006. Shedding Culture. Art from Start to Finish. Jazz, Painting, Writing and Other Improvisations. Chicago, London: University of Chicago Press.

Blumer, Herbert. 1969. Symbolic Interactionism. Perspective and Method. Englewood Cliffs, NJ: Prentice-Hall.

Carew, Peter J. and David Glynn. 2017 "Anti-Patterns in Agile Adoption: A Grounded Theory Case Study of One Irish IT Organisation." Global Journal of Flexible Systems Management 18(4):275-289. 
Chapman, Judith G. and Maureen H. Carrigan. 1993. "Public Self-Attention and Personal Standards: The Impact of Group Composition." Current Psychology 12:216-229.

Convertino, Gregorio and Nancy Frishberg. 2017. "Why Agile Teams Fail without UX Research." Communications of the ACM 60(9):35-37.

Cropley, Arthur J. 2011. “Definitions of Creativity." Pp. 511524 in Encyclopedia of Creativity, edited by M. A. Runco and S. R. Pritzker. San Diego, CA: Academic Press.

Cyran, Kazimierz and Sławomir Dybka. 2019. “The Influence of Prosumers on the Creation and the Process of Intelligent Products Flow." Pp. 241-257 in SMART Supply Network, edited by A. Kawa and A. Maryniak. Cham: Springer.

Dezutter, Stacey. 2011. "Professional Improvisation and Teacher Education." Pp. 27-50 in Structure and Improvisation in Creative Teaching, edited by K. Sawyer. New York: Cambridge University Press.

Glaser, Barney and Anselm L. Strauss. 1967. The Discovery of Grounded Theory: Strategies for Qualitative Research. New York: Aldine Publishing.

Gorzko, Marek. 2016. “Problem twórczości w generowaniu pojęć wprost $\mathrm{z}$ danych $\mathrm{w}$ świetle metodologii teorii ugruntowanej [The Issue of Creativity in Generating Concepts Directly from Data in the Light of the Grounded Theory Methodology]." Roczniki Nauk Społecznych 44(4):95-119.

Harris, Shanelle M. 2019. The Use of a Modified System Development Life Cycle (MSDLC) in a Sociological Environment to Improve Solution Validation. Retrieved October 04, 2020 (https://mdsoar. org/handle/11603/17664).

Highsmith, Jim. 2004. Agile Project Management: Creating Innovative Products. Boston: Addison Wesley.

Hodgson, Damian and Louise Briand. 2013. "Controlling the Uncontrollable: Agile Teams and Illusions of Autonomy in Creative Work." Work, Employment and Society 27(2):308-325.

Hormuth, Stefan. 1983. "Self-Awareness and Drive Theory: Comparing Internal Standards and Dominant Responses." European Journal of Social Psychology 12(1):31-45.

Hughes, Diane et al. 2016. The New Music Industries: Disruption and Discovery. Basingstoke: Palgrave MacMillan.
INTERREG IVC. 2014. Analysis Report. Creative Industries. Retrieved October 04, 2020 (https://cercles.diba.cat/documentsdigitals/pdf/E140303.pdf).

Jurney, Russell. 2014. Zwinna analiza danych. Apache Hadoop dla każdego [Agile Data Science: Building Data Analytics Applications with Hadoop]. Gliwice: Helion.

Katz, Jack. 1994. “Jazz in Social Interaction: Personal Creativity, Collective Constraint, and Motivational Explanation in the Social Thought of Howard S. Becker." Symbolic Interaction 17(3):253-279.

Konecki, Krzysztof T. 2018. Advances in Contemplative Social Research. Lodz: Wydawnictwo Uniwersytetu Łódzkiego / Cracow: Jagiellonian University Press.

Konecki, Krzysztof T. 2019. “Creative Thinking in Qualitative Research and Analysis." Qualitative Sociology Review 15(3):6-25.

Larman, Craig. 2004. Agile and Iterative Development: A Manager's Guide. Boston: Addison-Wesley.

McCall, George and J. L. Simmons. 1978. Identities and Interactions. New York: Free Press.

Mead, George H. 1926. "The Nature of Aesthetic Experience." International Journal of Ethics 36:382-392.

Mead, George H. 1934. Mind, Self and Society. Chicago: University of Chicago Press.

Morrow, Guy. 2018. "Distributed Agility: Artist Co-Management in the Music Attention Economy." International Journal of Arts Management 20(3):38-48.

Papadakis, Emmanouil and Loukas Tsironis. 2018. “Hybrid Methods and Practices Associated with Agile Methods, Method Tailoring and Delivery of Projects in a Non-Software Context." Procedia Computer Science 138:739-746.

Paris, Thomas and Sihem Ben Mahmoud-Jouini. 2019. "The Process of Creation in Creative Industries." Creative Innovation Management 28(3):1-17.

Paris, Thomas, Gerald Lang, and David Masse. 2020. “Polarized Worlds and Contextual Creativity in Creative Industries: The Case of Creation Processes in the Perfume Industry." Retrieved October 04, 2020 (https://ideas.repec.org/p/hal/journl/ hal-02104669.html). 
Petkus, Ed. 1996. "The Creative Identity: Creative Behavior from the Symbolic Interactionist Perspective." Journal of Creative Behaviour 30(3):188-196.

Ramesh, Balasubramaniam et al. 2017. "Conflicts and Complements between Eastern Cultures and Agile Methods: An Empirical Investigation." European Journal of Information Systems 26(2):206-235.

Reckwitz, Andreas. 2012. Odkrycie kreatywności [The Invention of Creativity]. Warsaw: Narodowe Centrum Kultury.

Sawyer, R. Keith. 2003. Group Creativity: Music, Theater, Collaboration. New York, London: Routledge.

Simon, Herbert. 1971. "Designing Organizations for an Information-Rich World." Pp. 38-72 in Computer, Communications, and the Public Interest, edited by M. Greenberger. Baltimore, MD: The Johns Hopkins Press.

Strauss, Anselm L. 1963. "The Hospital and Its Negotiated Order." Pp. 147-169 in The Hospital in Modern Society, edited by E. Freidson. New York: Free Press of Glencoe.
Ślęzak, Izabela. 2009. “Stawanie się poetą. Analiza interakcjonistyczno-symboliczna [Becoming a Poet. Interactionist-Symbolic Analysis]." Przeglad Socjologii Jakościowej 5(1).

Thibeault, Bernie. 2018. “A Complete Guide to Microsoft's Digital Feedback Loop." Retrieved October 04, 2020 (https://www. aerieconsulting.com/blog/microsofts-digital-feedback-loop).

Turner, Ralph. 1990. "Role Change." Annual Review of Sociology (16):87-110.

Vannini, Philipp and Waskul Dennis. 2006. "Symbolic Interaction as Music: The Esthetic Constitution of Meaning, Self, and Society." Symbolic Interaction 29(1):5-18.

Wiśniewski, Rafał and Tomasz Kukołowicz. 2017. “Pięć kierunków poszerzania pola kultury, czyli uwagi o współczesnej polityce kulturalnej [Five Directions of Expanding the Field of Culture-Comments on Contemporary Cultural Policy]." In Pomorskie poszerzenie pola kultury: dylematy - konteksty - dziatania [Pomeranian Expansion of the Field of Culture: Dilemmas - Contexts-Actions], edited by C. Obracht-Prondzyński and P. Zbieranek. Gdansk: Nadbałtyckie Centrum Kultury, Pomorskie Centrum Badań nad Kulturą UG.

\section{Citation}

Wiśniewski, Rafał and Izabela Bukalska. 2020. "The Interactive Dimension of Creating Cultural Artifacts Using Agile Methodologies." Qualitative Sociology Review 16(4):198-210. Retrieved Month, Year (http://www.qualitativesociologyreview.org/ENG/ archive_eng.php). DOI: http://dx.doi.org/10.18778/1733-8077.16.4.12 